\title{
Evaluation Model of Urban Land Use Efficiency Based on Super-Efficiency-DEA
}

\author{
Yingying Qiu ${ }^{1, a}$, Jia Sheng ${ }^{1, b}$ and Xiaoyu $\mathrm{He}^{1, \mathrm{c}}$ \\ ${ }^{1}$ School of Civil and Environment Engineering, Anhui Xinhua University, Hefei, Anhui, 230088, \\ China \\ aqyy_hust121@126.com, ${ }^{b} 382342228 @ q q . c o m,{ }^{c} 76598085 @ q q . c o m$
}

\section{Keywords: Urban Land Use Efficiency, Super Efficiency DEA, Evaluation, WuHan}

Abstract. With the accelerating of urbanization in China, the urban land use efficiency has relationship to allocation of resources, and has influence on the quality of human life and sustainable development. Aiming at the shortage that traditional DEA model can't make further evaluation on effective Decision Making Unit, this paper established the evaluation model of urban land use efficiency based on super efficiency DEA, and applied the model to evaluate the land utilization efficiency in 13 districts of Wuhan. The results show that super efficiency DEA method can effectively solve the problem of ranking the decision units completely, the evaluation result is more fairness and reference, and it can also provide a reference for the government to make reasonable land use policy.

\section{Introduction}

With increasing in urbanization and industrialization in China, the urban land demand will increase gradually, which requires higher benefits of urban land use. However, there are some general problems for the use of urban land resources at present, such as rapid expansion of city scale, quick decrease of arable land, unreasonable structure of land use, low use efficiency [1].

The land use efficiency refers to the ability to achieve maximum economic output under the conditions of a given land investment, or the ability to achieve minimum land investment with a level of a given economic output. Wu and Yeh (1996)[2], on the basis of studying urban land use situation of Guangzhou in China, analyze the influencing factors of land use efficiency using logistic regression. David M (2006)[3] put forward using linear regression method to measure the land use efficiency. In China, the evaluation method of urban land use efficiency has constantly been developed, the research method has increasingly diversified, mainly including the principal component analysis (PCA), fuzzy comprehensive evaluation method, analytic hierarchy process (AHP), regression analysis and data envelopment analysis (DEA). In recent years, more and more scholars try to use DEA method to evaluate urban land use efficiency. DEA method adopt the optimization method to determine the weight of each input element, it don't need to determine the specific functional relation between input and output, and avoid the errors because of function relationship as well as the inaccuracy caused by the subjectivity of determining each index weigh effectively, its unique advantage make the DEA method have been widely applied in the evaluation of land use efficiency[4]. Such as, the CCR-DEA method is applied to evaluate land use efficiency of 17 cities in Shandong province by Xiaoming Wang (2005) [5], selecting land usable area, capital input and the workers as the input index of land use, the second and third industries as economic output index of land use. Liangyue Zhang (2009)[6] uses DEA to make an empirical analysis on land use efficiency of prefecture city in China. Dewen $\mathrm{Wu}(2011)$ [7] uses DEA model to evaluate the land use relative efficiency of 33 cities in China, and the input and output elements are analyzed in his paper. Liutao Liang (2013)[8] uses DEA model to analyze the spatial distribution characteristics of land use efficiency of 287 prefecture-level cities in China in 2011, and the path of optimizing land use are discussed in this paper.

However, these studies have the deficiency that existing research using the DEA method could not distinguish and compare the efficiency difference further between the effective decision making units (efficiency value is 1). In view of the shortage of the existing literature research, Super-efficiency DEA 
model is put forward to measure and distinguish urban land use efficiency, and a practical example analysis of land use efficiency 13 districts in Wuhan is carried out.

\section{Research Method}

The Data Envelopment Analysis (DEA) was proposed in 1978 by the operational research experts of A. Charnes and W.W. Cooper, DEA is an evaluation method for efficiency which is developed on the basis of the concept of relative efficiency. The effective production frontier is estimated based on a set of input and output observations first, if the corresponding point of decision making unit is on the effective production frontier, the decision making unit is considered to be effective.

The advantage of DEA method is that it can process efficiency evaluation about multiple input and output, and the weight of assessment indexes are determined by applying the optimization method, so as to avoid the subjective random of determining the weight. The traditional DEA models are CCR-DEA and BCC-DEA models[4], both of the two models only divide the DMU into efficient and inefficient, so they can't distinguish the efficiency difference among decision making units completely. Therefore, the Super-efficiency DEA which is proposed by Andersen and Petersen is applied in this thesis[9]. The model is expressed in Eq.1.

$$
\left\{\begin{array}{l}
\min \theta \\
s . t \\
\sum_{\substack{k=1 \\
k \neq l}}^{n} X_{k} \lambda_{k}+s^{-}=\theta X_{l} \\
\sum_{k=1}^{n} Y_{k} \lambda_{k}-s^{+}=Y_{l} \\
k \neq l \\
\lambda_{k} \geq 0, k=1,2, \mathrm{~L} \quad n \\
s^{-} \geq 0, s^{+} \geq 0
\end{array}\right.
$$

In the expression, $\theta$ is the efficiency value of decision making unit, if $\theta \geq 1$, the decision making unit will be considered to be effective, otherwise, the decision making unit will be invalid.

\section{The Empirical Analysis}

Index Systems and Data Sources. For the selection of indicators of inputs and outputs in DEA model, on the basis of existing literatures, considering the quantization of indicators, the characteristics of DEA model as a method of evaluating relative efficiency and the availability of data, in terms of input indexes, according to Cobb - Douglas function, land, capital and labor are the important factors of production. For land input, the area of city is a reasonable index, for capital input, some scholars select fixed asset funding as an instead indicator, the calculation results are high in reliability, so this paper also select urban fixed asset funding as a instead indicator of capital investment. For the labor input indicator, the paper selects the number of people employed in the secondary and tertiary industry. In terms of output indexes, most of scholars choose local fiscal revenue, the added value of secondary and tertiary industry, gross domestic product (GDP) and urban per capita disposable income to reflect the land output, the paper also select these indicators as output index. However, from the perspective of scientific analysis, the evaluation of urban land use efficiency should consider environmental benefits, the index reflecting the environmental benefit is difficult to quantify and obtain, so the output indicators reflecting environmental benefits aren't selected in this paper.

The quantitative data that is used in the paper comes from statistical yearbook in Wuhan Hubei province of 2013, web site statistical information of statistical bureau of Hubei province and districts. The administrative zoning map of Wuhan is shown in Fig 1. 


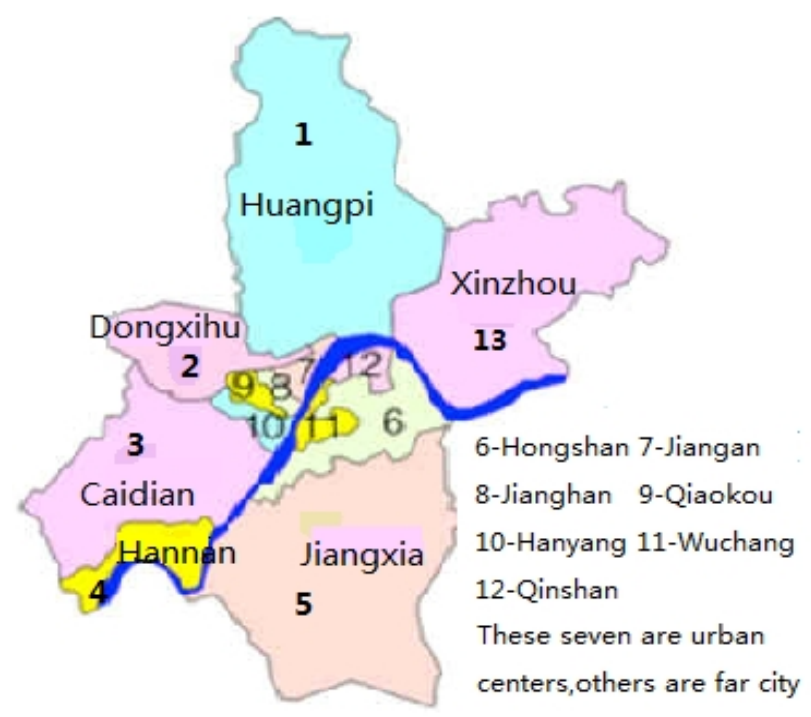

Fig 1 The administrative zoning map of Wuhan Hubei province

The Measurement of Land Use Efficiency of Wuhan. Taking the system composed of 13 districts in Wuhan as research objects, super efficiency DEA model and EMS (Efficiency Measurement System, Version 1.3.0) software are used to calculate the land use super efficiency value (SE) of every district in Wuhan in 2012, at the same time, use CCR-DEA and BCC-DEA in DEAP 2.1 software to calculate the comprehensive efficiency, pure technical efficiency and scale efficiency value of land use, and compare with super efficiency value. The results are shown in table 1.

Table 1 The evaluation results of land use efficiency of Wuhan in 2012

\begin{tabular}{|c|c|c|c|c|c|c|}
\hline \multirow[b]{2}{*}{ District } & \multirow{2}{*}{$\begin{array}{c}\text { CCR-DEA } \\
\begin{array}{c}\text { comprehensive } \\
\text { efficiency }\end{array}\end{array}$} & \multicolumn{2}{|c|}{ BCC-DEA } & \multirow{2}{*}{$\begin{array}{l}\text { Returns } \\
\text { to scale }\end{array}$} & \multirow{2}{*}{$\begin{array}{c}\text { SE-DEA } \\
\text { super } \\
\text { efficiency }\end{array}$} & \multirow[b]{2}{*}{ Sorting } \\
\hline & & $\begin{array}{l}\text { technical } \\
\text { efficiency }\end{array}$ & $\begin{array}{c}\text { scale } \\
\text { efficiency }\end{array}$ & & & \\
\hline Jiangan & 1.000 & 1.000 & 1.000 & - & 1.054 & 10 \\
\hline Jianghan & 1.000 & 1.000 & 1.000 & - & 2.418 & 2 \\
\hline Qiaokou & 0.884 & 0.951 & 0.930 & irs & 0.884 & 13 \\
\hline Hanyang & 1.000 & 1.000 & 1.000 & - & 1.589 & 7 \\
\hline Wuchang & 1.000 & 1.000 & 1.000 & - & 1.101 & 9 \\
\hline Qingshan & 1.000 & 1.000 & 1.000 & - & 1.982 & 5 \\
\hline Hongshan & 1.000 & 1.000 & 1.000 & - & 2.285 & 3 \\
\hline Dongxihu & 1.000 & 1.000 & 1.000 & - & 4.041 & 1 \\
\hline Hannan & 1.000 & 1.000 & 1.000 & - & 2.226 & 4 \\
\hline Caidian & 0.892 & 0.902 & 0.989 & irs & 0.892 & 12 \\
\hline Jiangxia & 1.000 & 1.000 & 1.000 & - & 1.645 & 6 \\
\hline Huangpi & 1.000 & 1.000 & 1.000 & - & 1.247 & 8 \\
\hline Xinzhou & 1.000 & 1.000 & 1.000 & - & 1.026 & 11 \\
\hline
\end{tabular}

(1) The analysis based on CCR-DEA and BCC-DEA model

Table 1 shows that the number of effective districts of 13 districts in Wuhan in 2012 is 11, only two districts are invalid. For invalid districts, such as Qiaokou and Caidian District, the comprehensive efficiency, pure technical efficiency and scale efficiency value of the two districts are different, we can analysis and compare the level of the two districts' land use efficiency by comparing the three efficiency value. But for effective districts, because of comprehensive efficiency value $=$ pure technical efficiency valuex scale efficiency value, it can be known that the pure technical efficiency and scale efficiency value of effective districts are 1 as well, and their scale reward don't change. For the 11 effective districts, it can't further distinguish efficiency difference among them from comprehensive efficiency, pure technical efficiency and scale efficiency. Therefore, CCR-DEA and BCC-DEA model can't distinguish the efficiency difference among effective districts when there are more availability decision-making units. 
(2) The analysis based on Super-efficiency DEA model

To solve this problem that CCR-DEA and BCC-DEA model can't distinguish further the efficiency difference among effective districts, this paper use super efficiency DEA model to calculate the efficiency value of 13 districts. The results show that: the super efficiency value of invalid districts is the same efficiency values calculate by CCR-DEA model, and the super efficiency value of effective districts are different, so you can evaluate and rank further effective districts. Based on the sorted data in Table 1 Dongxihu district tops the list of land use efficiency of Wuhan in 2012, its value is 4.041, followed by Jianghan, Honagshan, Hannan, Qingshan, Jiangxia, Hanyang, Huangpi, Wuchang, Jiangan and Xinzhou. The super efficiency value of Xinzhou is 1.026, it is observed that the land use efficiency has a big gap among effective districts.

\section{Conclusions}

To solve this problem that CCR-DEA and BCC-DEA model can't distinguish further the efficiency difference among effective districts, the paper propose using super efficiency DEA model to evaluate land use efficiency. Based on the model, an empirical analysis is conducted to analyze the land use efficiency of Wuhan, the results show that the super efficiency DEA model can measure and distinguish the efficiency among different decision making units effectively.

\section{Acknowledgement}

This study is supported by National Social Sciences Fund Project, the number is 12CJY066.

\section{References}

[1] Xinwei Liu. The Land Use Problems in Stage of China's Fast Urbanization. Land and Resources Information, vol. 12(2006), p. 22-29. (In Chinese)

[2] Fulong Wu, Yeh Anthony Gar-On. The new land development process and urban development in Chinese cities. International Journal of Urban and Regional Studies, vol. 20(1996), p. 330-353.

[3] David M, Eligius MT, etal. A Framework to Study Nearly Optimal Solutions of Linear Programming Models Developed for Agricultural Land Use Exploration. Ecological Modeling, vol. 131(2006), p.65-77.

[4] Charnes A, Cooper W. W. Measuring the Efficiency of DMU. European Journal of Operational Research, vol. 2(1978), p.429-444.

[5] Xiaoming Wang and Hongwen Yan. DEA Method for Evaluating the Efficiency of the Urban Land Utilization. Journal of Shandong Agriculture University, vol. 36(2005), p. 573-576. (In Chinese)

[6] Liangyue Zhang, Bo Shi, Dong Liu. The Regional Difference of China's Urban Land Use Efficiency. Economic Review, vol. 4(2009), p. 18-26. (In Chinese)

[7] Dewen Wu, Hanying Mao. Assessment of Urban Land Use Efficiency in China. Economic Geography, vol. 20(2011), p. 84-89. (In Chinese)

[8] Liutao Liang, Qinliang Zhao and Cong Chen. Analysis on the Characters of Spatial Disparity of Urban Land Use Efficiency and Its Optimization in China. China Land Sciences, vol. 27(2013), p. 48-54. (In Chinese)

[9] Andersen P, Petersen N C. A Procedure for Ranking Efficient Units in Data Envelopment Analysis. Management Science, vol. 39(1993), p.1261-1264. 